\title{
Microanalysis of Very Fine Precipitates by FE-SEM
}

\author{
A.M. Elwazri, R. Varano, F. Siciliano ${ }^{1}$, R. Gauvin and S. Yue \\ Department of Metals and Materials Engineering, McGill University 3610 University St., Montréal, \\ Quebec, Canada, H3A 2B2. \\ ${ }^{1}$ Reference Metals Company, Inc. 1000 Old Pond Rd. Bridgeville, PA, 15017, USA.
}

Field emission gun scanning electron microscope (FE-SEM) conventionally uses bulk specimens. Therefore, there is a problem of the interaction volume lowering the resolution of the microscope. This limitation in the FE-SEM can be alleviated by using thin specimens such as carbon extraction replicas. Therefore, the aim of this work was to develop a technique to examine fine $\mathrm{Nb}$ precipitates in carbon extraction replicas in the FE-SEM.

The chemical composition of the steel can be seen in Table 1. The specimens were austenitised for $20 \mathrm{~min}$ at $1200^{\circ} \mathrm{C}$, and then cooled to the test temperature $\left(400^{\circ} \mathrm{C}\right)$, and were held for 5 minutes in order to homogenize the temperature within the specimen. The specimens were then deformed to a strain of 0.06 at a constant strain rate of $1 / \mathrm{s}$ and held for 1 hour at this temperature.

It should be reiterated that the goal of the present work was to analyze very fine particles (below 50 $\mathrm{nm}$ ) and take advantage of the high peak-to-background ratio by using higher accelerating voltages for chemical analysis. Practically speaking, reducing the interaction volume through the use of carbon extraction replicas translates to a higher x-ray count generated by the embedded particles. In general, there were numerous particles below 50nm throughout the replicas, but for the sake of brevity one example will be given to illustrate the effect of voltage on the signal generated from a $20 \mathrm{~nm}$ size particle. In a normal bulk sample, such particles would be difficult to identify. However, this was not the case when using carbon extraction replicas. The SE images of the 20nm particle (Fig. 1) were taken at the following accelerating voltages: $5 \mathrm{kV}, 10 \mathrm{kV}$ and $15 \mathrm{kV}$.

Even at $5 \mathrm{kV}$, a clear peak could be seen for $\mathrm{Nb}$ proving that the particle was in fact a $\mathrm{Nb}$ precipitate. And as expected, by increasing the accelerating voltage the $\mathrm{Nb}$ peak also increased (Fig. 2) in intensity. For comparative purposes the corresponding peak-to-background ratios were: 4.4, 7.1 and 7.9 for $5 \mathrm{kV}, 10 \mathrm{kV}$ and $15 \mathrm{kV}$, respectively. In addition to $\mathrm{Nb}$, other elemental peaks could be detected from the surrounding materials. The $\mathrm{Al}$ and $\mathrm{Si}$ peaks were generated from the holder (the $\mathrm{O}$ peak was visible due to oxidation of the holder itself), the Ni peak originated from the sample grid and the extraction replica was mainly responsible for the $\mathrm{C}$ peak. (Note: $\mathrm{N}$ was not observed in these particles, possibly due to strong absorption by carbon.). For example, a 10nm size particle was selected (Fig. 3a) and a spot analysis was conducted. From the acquired spectrum (Fig. 3b), the particle was identified as another $\mathrm{Nb}$ precipitate. Prior to this study, it was certain that $\mathrm{Nb}$ precipitates as particles above $50 \mathrm{~nm}$ in steel, but identifying precipitates below this size was not clarified. However, from this analysis conducted on carbon extraction replicas using an FE-SEM, it was proven that $\mathrm{Nb}$ can indeed precipitate as particles below 50nm (as low as $10 \mathrm{~nm}$ ). FE-SEM was successfully used in characterizing $\mathrm{Nb}$ precipitate as low as $10 \mathrm{~nm}$ (comparable to the capabilities of a TEM). It was found that by increasing the accelerating voltage from $5 \mathrm{kV}$ to $15 \mathrm{kV}$ improved the EDS acquisition by taking advantage of the high peak-to-background ratio inherent in thin specimens, such as carbon extraction replicas, due to the small interaction volume. 

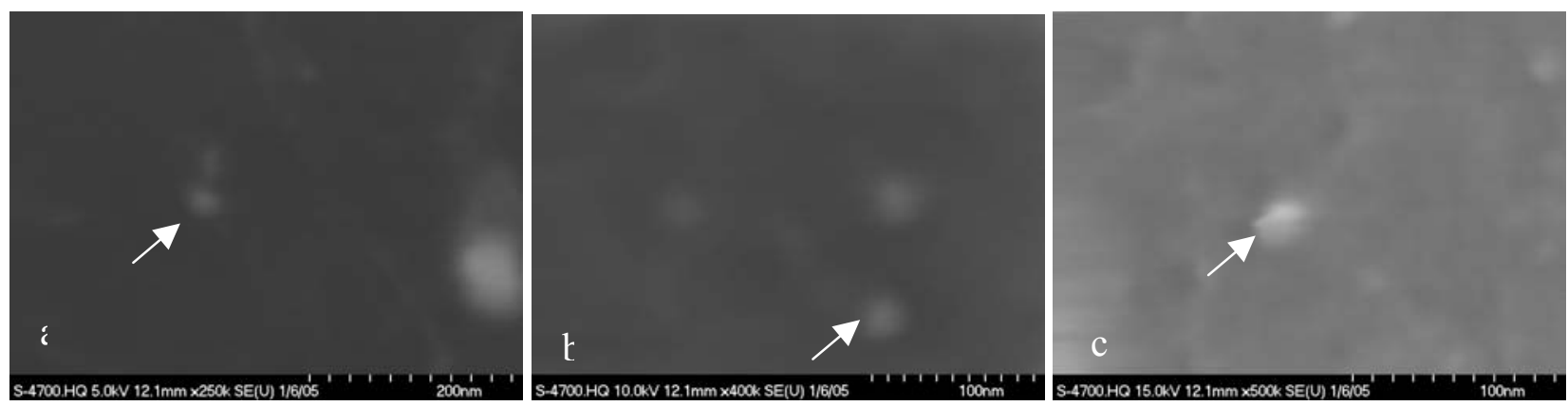

Fig. 1. SE images of $20 \mathrm{~nm}$ size particle taken at various accelerating voltages: (a) $5 \mathrm{kV}$, (b) $10 \mathrm{kV}$ and (c) $15 \mathrm{kV}$ (arrows delineate particle).
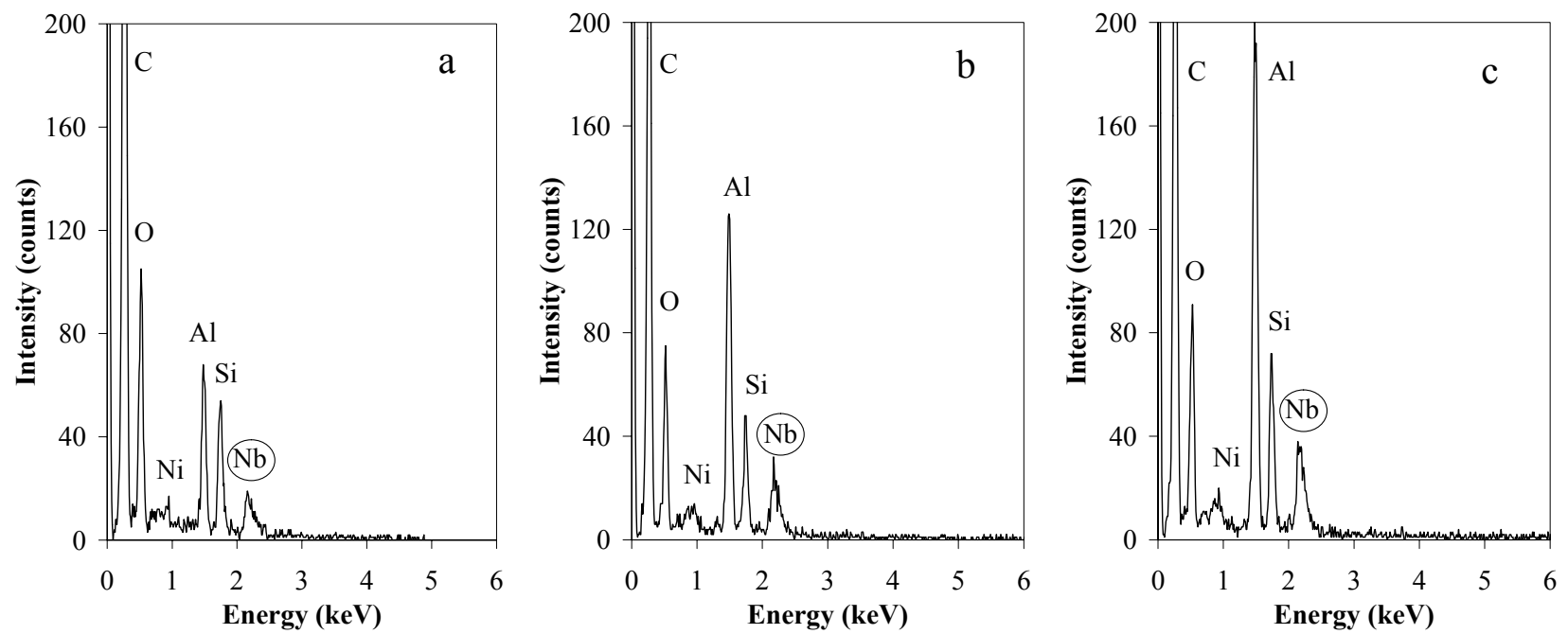

Fig. 2. EDS spectra of $20 \mathrm{~nm}$ size particle taken at various accelerating voltages: (a) $5 \mathrm{kV}$, (b) $10 \mathrm{kV}$ and (c) $15 \mathrm{kV}$.
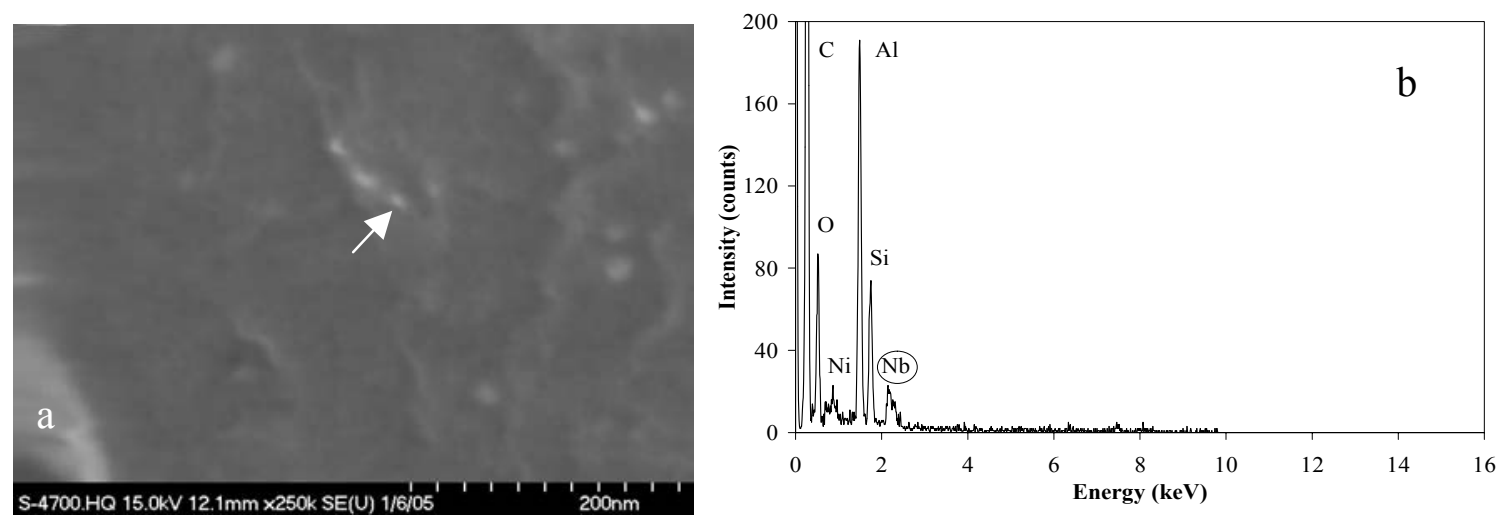

Fig. 3. FE-SEM analysis of 10nm size precipitate: (a) SE image of particle and (b) EDS spectrum showing $\mathrm{Nb}$ peak

Table 1. Chemical composition of steel (wt\%)

\begin{tabular}{|c|c|c|c|c|c|c|c|c|}
\hline $\mathbf{C}$ & $\mathbf{M n}$ & $\mathbf{S i}$ & $\mathbf{C u}$ & $\mathbf{N i}$ & $\mathbf{C r}$ & $\mathbf{T i}$ & $\mathbf{N}$ & Others \\
\hline 0.038 & 1.84 & 0.28 & 0.42 & 0.13 & 0.06 & 0.017 & 0.0092 & Mo Nb \\
\hline
\end{tabular}

